\title{
Análise Fatorial do Sistema Agroindustrial do Biodiesel no Brasil e na União Europeia ${ }^{1}$
}

\author{
Bárbara Françoise Cardoso², Pery Francisco Assis Shikida ${ }^{3}$ e Adele Finco ${ }^{4}$
}

Resumo: Este artigo objetiva analisar comparativamente os principais fatores envolvidos na coordenação do sistema agroindustrial do biodiesel (SAI biodiesel) no Brasil e na União Europeia, sob a perspectiva dos stakeholders deste sistema. Para tanto, foi desenvolvido um questionário e a comparação foi realizada por meio da análise fatorial. Os resultados mostraram que os fatores semelhantes estão relacionados à tributação e ao comércio internacional, aos sindicatos dos trabalhadores e associações que representam as usinas de biodiesel, e à diversificação, aquisição da agricultura familiar/pequeno produtor e garantia de oferta. Os fatores diferentes são: (1) no Brasil: estratégias de crescimento, competitividade das usinas, diferenciação das usinas, incentivos para a produção de biodiesel, políticas gerais sobre biocombustíveis, tecnologias de produção de biodiesel e políticas nacionais específicas e (2) na UE: diferenciação na produção de biodiesel e organizações de apoio. Os resultados também mostraram a existência de um trade-off no que se refere ao avanço tecnológico no SAI biodiesel. Se, por um lado, a inclusão dos agricultores familiares e pequenos agricultores na economia é um dos fatores a serem considerados para a sustentabilidade do sistema, por outro, o desenvolvimento deste, buscando resolver o conflito alimento versus biocombustíveis, marginaliza estes produtores.

Palavras-chaves: Sistema Agroindustrial do Biodiesel, Brasil, União Europeia, Análise Fatorial.

\begin{abstract}
This paper aims to analyze comparatively the main factors involved in the coordination of the agro-industrial system of biodiesel (AIS of biodiesel) in Brazil and the European Union, from the perspective of the stakeholders of this system. For this, a questionnaire was developed and the comparison was done by factor analysis. The results showed that similar factors are related to taxation and international trade, labor unions and associations representing the biodiesel plants and diversification, acquisition of family farming/small producer and guaranteeing supply. The different factors are: (1) in Brazil: growth strategies, competitiveness of plants, differentiation of plants, incentives for biodiesel production, general policies on biofuels, biodiesel production technologies

1. Data de submissão: 20 de maio de 2016. Data de aceite: 11 de junho de 2017.

2. Universidade Estadual do Oeste do Paraná (Unioeste). Toledo, Paraná, Brasil. E-mail: barbarafcardoso@gmail.com

3. Universidade Estadual do Oeste do Paraná (Unioeste). Toledo, Paraná, Brasil. E-mail: peryshikida@hotmail.com

4. Università Politecnica delle Marche. Ancona, Marche, Italia. E-mail: a.finco@univpm.it
\end{abstract}


and specific national policies and (2) in the the European Union: differentiation in the production of biodiesel and support organizations. The results also showed the existence of a trade-off regarding to the technological advances on the AIS of biodiesel. If, on the one hand, the inclusion of family farmers and smallholders in the economy is one of the factors to be considered for the sustainability of the system, on the other hand, the development of this, seeking to resolve the conflict food versus biofuels, marginalizes these producers.

Key-words: Agro-industrial System of Biodiesel, Brazil, European Union, Factor Analysis.

Classificação JEL: Q16, Q18, Q42, Q48.

DOI: http://dx.doi.org/10.1590/1234-56781806-94790550308

\section{Introdução}

Os estudos sobre o uso de óleos vegetais para a produção de combustíveis datam do final do século XIX. Em 1895, Rudolf Diesel percebeu que os óleos vegetais poderiam ser utilizados como combustível, favorecendo o desenvolvimento industrial. Em 1900, Diesel apresentou, em uma Exposição Mundial em Paris, o primeiro motor de ignição por compressão movida a combustível - na ocasião foi utilizado o óleo de amendoim. Contudo, a disponibilidade de petróleo na época, o avanço desta indústria e o aumento da demanda por automóveis, além de outros fatores, fizeram com que os estudos sobre os óleos vegetais, enquanto combustíveis, fossem mantidos em segundo plano. Além do mais, o petróleo mostrava-se mais rentável do que os óleos vegetais. Com isso, os derivados de petróleo passaram a ser considerados o combustível padrão utilizado em todo o mundo.

Na década de 1970, as consequentes crises do petróleo em consonância com a crescente preocupação ambiental proporcionaram a retomada dos estudos de viabilidade do uso de óleos vegetais nos motores veiculares. Neste contexto, a produção e o uso de fontes renováveis de energia passaram a receber mais atenção, não somente por serem substitutos potenciais dos derivados de petróleo, mas também por emitirem menos gases poluentes, já que a preocupação com o meio ambiente passou a ser mais acentuada devido, principalmente, às mudanças climáticas.

Com as atenções voltadas às energias renováveis, as pesquisas técnicas sobre o uso de biocombustíveis nos motores veiculares se intensificaram em todo o mundo. Alguns países, no decorrer dos anos, especializaram-se na produção deste tipo de combustível, proporcionando o surgimento de sistemas agroindustriais locais, tais como o Brasil e os Estados Unidos, que se particularizaram na produção de etanol; e os países da Europa, que se individualizaram na produção de biodiesel.

A produção de biocombustíveis em alguns países tem implicação de risco e benefício no que concerne ao mercado agrícola, na segurança alimentar e no meio ambiente, sendo este último relacionado com mudanças climáticas e no uso do solo. Além disso, existe um conflito de escolha (trade-off) que deve ser considerado, pois a produção de biocombustíveis em geral, de um lado produz benefícios ao meio ambiente ao reduzir a emissão de gases de efeito estufa, porém, podem causar prejuízos às culturas alimentares, seja pela competição de produção e preço, seja pela mudança do uso do solo (ZEZZA, 2008).

Neste contexto mundial em que se inserem os biocombustíveis, o sistema agroindustrial do biodiesel (SAI biodiesel) vem ganhando importância econômica e ambiental nos diversos países. Este sistema agrega todas as operações necessárias para a produção e comercialização do biodiesel, envolvendo desde a produção de matérias-primas até a chegada do biodiesel ao consumidor final, além de toda a legislação que envolve a produção e o uso de biodiesel, e as organizações de apoio, tais como aquelas relacionadas à infraestrutura, comunicação, transporte, entre outras. 
As diferenças no sistema agroindustrial de cada país e a forma como é vista a produção, seja de biodiesel seja de suas matérias-primas, são fatores ainda pouco estudados na literatura. Obviamente, as diferenças edafoclimáticas e culturais evidenciam algumas das distinções dentro de cada sistema agroindustrial. Contudo, há semelhanças que podem ser encontradas no que concerne ao SAI biodiesel, principalmente se analisadas as perspectivas dos stakeholders deste sistema, já que os objetivos da produção e uso de biodiesel são os mesmos, independentemente do país onde é produzido. Evidenciar tais diferenças e semelhanças é útil para melhorar a coordenação do sistema agroindustrial em cada país, pois as experiências alheias, principalmente na visão dos stakeholders envolvidos no sistema, podem mostrar falhas que a legislação não considera e detectar deficiências a serem aprimoradas.

Isto posto, o objetivo desta pesquisa é analisar comparativamente os principais fatores envolvidos na coordenação do SAI biodiesel no Brasil e na União Europeia, sob a perspectiva dos stakeholders deste sistema agroindustrial em ambos os contextos.

\section{Sistema Agroindustrial do Biodiesel: caracterização geral}

De acordo com Batalha (1997), um sistema agroindustrial (SAI) refere-se à análise de todo o conjunto de atividades e processos relacionados à produção de um determinado produto agroindustrial, desde a produção dos insumos utilizados para a produção agropecuária até a chegada do produto final ao consumidor. O conceito não está relacionado a uma matéria-prima agropecuária específica (porque pode ser utilizada mais de uma matéria-prima para a obtenção de um determinado produto) nem a algum produto agroindustrial específico (pois a partir de uma mesma matéria-prima pode-se obter mais de um produto). Ou seja, o SAI pode ser caracterizado como um conjunto de cadeias produtivas, sendo definido a partir de suas matérias-primas ou de seus produtos finais.

Zylbersztajn (2000, p. 13) expõe as dimensões do SAI, alegando que este pode ser visto como "um conjunto de relações contratuais entre empresas e agentes especializados, cujo objetivo é disputar o consumidor de determinado produto". A relação entre os stakeholders, de forma geral, adaptada para o SAI biodiesel, está exposta na Figura 1.

As matérias-primas utilizadas para a produção de biodiesel são, mormente, as oleaginosas, sendo que os principais óleos vegetais utilizados são o óleo de soja, de mamona, de canola, de girassol, de algodão e de palma. Também são usados em escala comercial o sebo animal e o óleo residual de fritura de uso doméstico, comercial e industrial. O óleo de microalgas e os resíduos provenientes de tratamento de esgotos são usados em escala menor e/ou em fase experimental em alguns países (ROSILLO-CALLE et al., 2009).

Tendo em vista que o biodiesel não possui um comércio internacional consolidado, o segmento de distribuição do SAI biodiesel deve ser analisado em separado dentro de cada país conforme o tipo de matéria-prima utilizada. No segmento de distribuição deve-se considerar o transporte da matéria-prima até a

Figura 1. Sistema agroindustrial

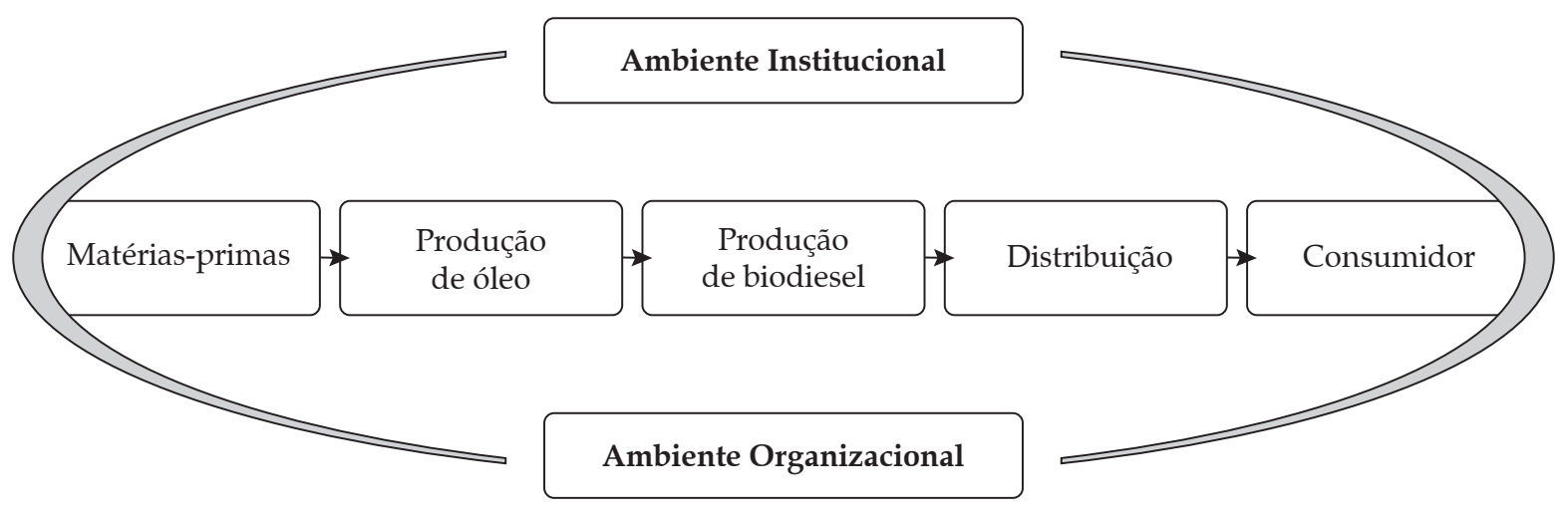

Fonte: Adaptado de Zylbersztajn (1995). 
usina de biodiesel e o transporte deste biocombustível até as distribuidoras. Tal transporte pode ser realizado por meio de ferrovias, rodovias e/ou dutos. No que concerne ao consumo de biodiesel, de acordo com Sungate (2015), os principais consumidores são a União Europeia, Estados Unidos, Brasil, Indonésia, China, Argentina, Tailândia e Malásia, sendo que os países da Europa são responsáveis por cerca de $80 \%$ do consumo mundial.

\subsection{Características do sistema agroindustrial do biodiesel no Brasil}

No Brasil, a produção de biodiesel é proveniente, em sua maioria, de óleos vegetais e sebo animal. No início da produção comercial de biodiesel, o Brasil uti- lizava mais de $70 \%$ de óleo de soja como matéria-prima principal (AGÊNCIA NACIONAL DO PETRÓLEO, GÁS NATURAL E BIOCOMBUSTÍVEIS - ANP, 2015). A produção em escala comercial iniciou-se em março de 2005, com uma produção de 736,16 $\mathrm{m}^{3}$. Desde então, a produção vem aumentando (com taxa geométrica de crescimento de 83,23\%), chegando, em 2015, a 3,9 milhões de $\mathrm{m}^{3}$. A Figura 2 mostra a evolução da produção de biodiesel no Brasil.

Em termos de consumo de biodiesel, até 2010 o Brasil apresentou crescimento exponencial, a uma taxa geométrica de $245,9 \%$, caracterizado principalmente pela obrigação de mistura do biodiesel ao óleo diesel que passou de 2\% em 2005 para 5\% em 2010. A partir de 2010, o aumento no consumo apresentou leve acréscimo, como mostra a Figura 3.

Figura 2. Produção de biodiesel no Brasil

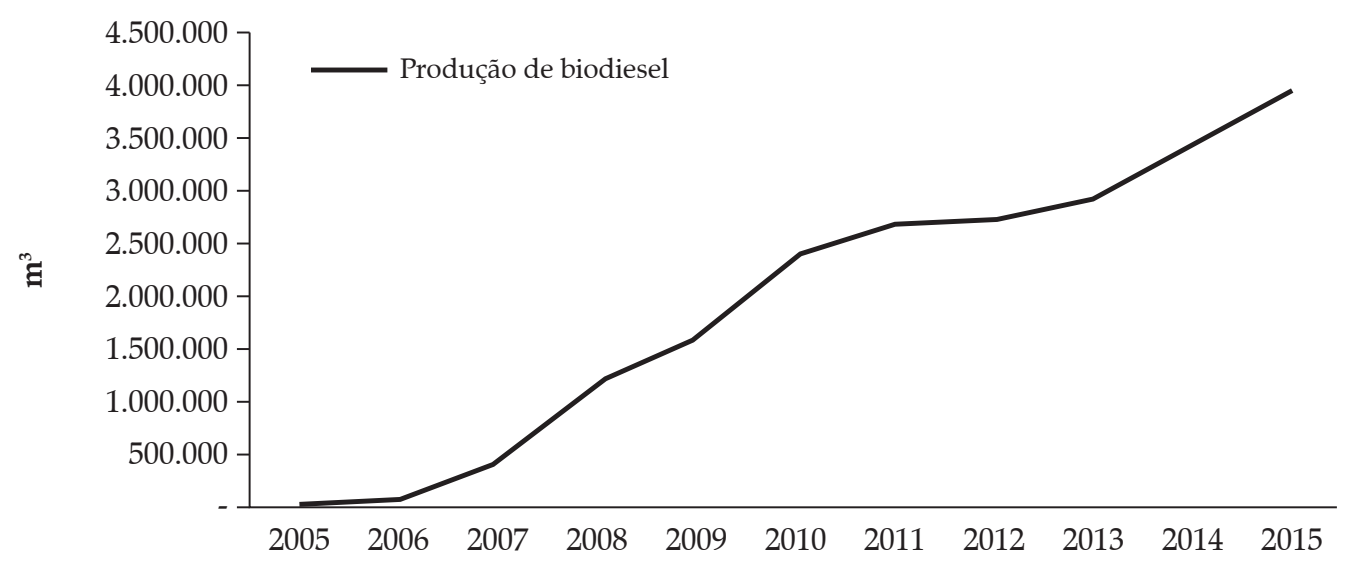

Fonte: Elaboração própria por meio dos dados da ANP (2015).

Figura 3. Evolução do consumo de biodiesel no Brasil

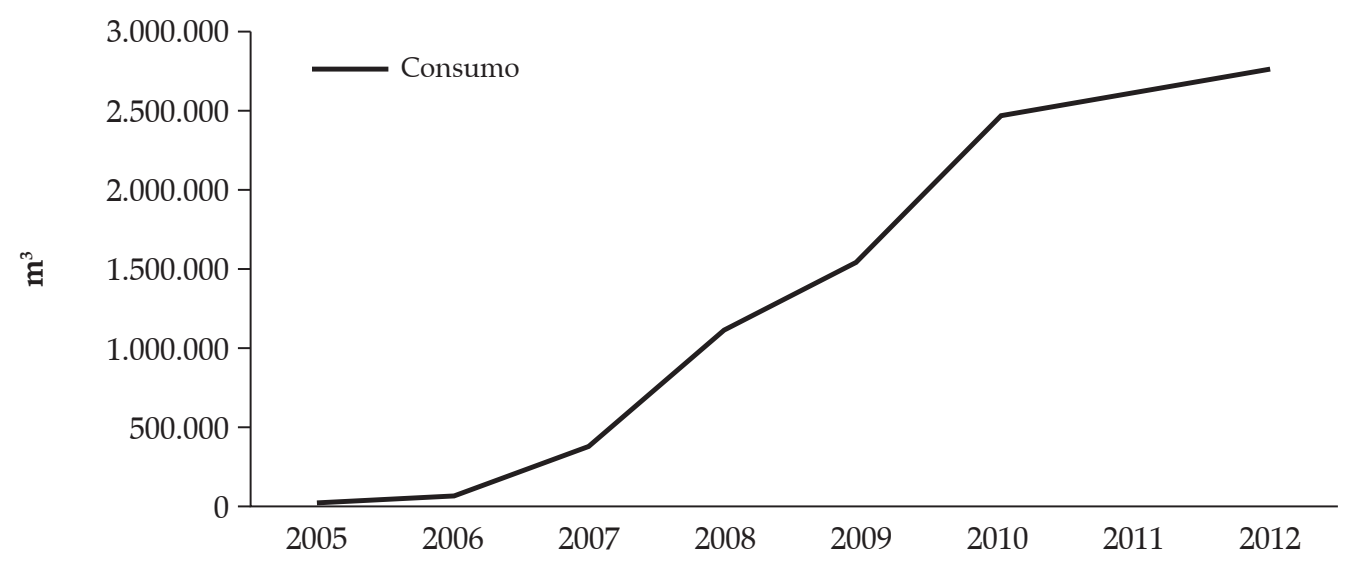

Fonte: Energy Information Admnistration - EIA (2015). 
O consumo brasileiro de biodiesel aumentou de 3,5 mil m³ em 2005 para 2,8 milhões de m $^{3}$ em 2012. Este aumento apresentou taxa geométrica de 133,9\%. O biodiesel é utilizado no setor de transporte em mistura com o óleo diesel. Dessa forma, não somente os mandatos de biodiesel (BX) influenciaram o aumento da produção e do consumo de biodiesel no Brasil, mas também o aumento da frota de veículos movidos a óleo diesel. Além disso, o setor de aviação no Brasil também está investindo no uso de biodiesel enquanto combustível (UNIÃO BRASILEIRA DO BIODIESEL E BIOQUEROSENE - UBRABIO, 2015).

No que concerne ao comércio internacional, vale lembrar que o Brasil ainda não tem um mercado consolidado. Todavia, Beckman (2015) afirma que o País iniciou as transações externas em 2006, como mostra a Figura 4.

Em relação ao mercado nacional, Chagas (2012) afirma que ele pode ser caracterizado como competitivo, uma vez que é regido pela estrutura de governança de leilões em que há grande número de produtores e de potenciais compradores. Segundo Chagas (2012, p. 73), "o grande desafio para o setor de biodiesel brasileiro é o de se desassociar da cadeia produtiva da soja. O setor, no curto e médio prazos, deveria buscar uma matéria-prima que fosse mais produtiva em termos de litro de biodiesel equivalente por hectare, e que não fosse utilizada diretamente como alimento". Neste sentido, a diversificação de matérias-primas, incluindo as não agrícolas, seria uma das possíveis soluções para minimizar este problema.

\subsection{Características do sistema agroindustrial do biodiesel na União Europeia}

A produção de biodiesel na União Europeia é proveniente, em sua maioria, de óleos vegetais, principalmente de canola e de palma. Em 2013, a União Europeia produziu 10,3 milhões de toneladas de biodiesel, aumento de $873 \%$ em relação a 2002. A Alemanha se mostra como o principal país produtor, com uma produção de 2,5 milhões de toneladas, seguido da França (1,9 milhão de toneladas), Espanha (618 mil toneladas) e Itália (387 mil toneladas), representando, juntos, 52\% da produção europeia em 2013 (EUROPEAN BIODIESEL BOARD - EBB, 2015). A Figura 5 mostra a evolução da produção europeia de biodiesel.

Em relação ao consumo de biodiesel, apresentou aumento de $1.185 \%$ de 2002 a 2012 no setor de transporte da União Europeia (EU-28). Contudo, a partir de 2013 é observada, pela primeira vez, uma redução do consumo, de 7,8\% de 2012 a 2013, devido à falta de incentivos na produção e ao aumento das barreiras para importação de matérias-primas, dificultando o acesso ao biodiesel pelo consumidor. Em 2013, a França era a principal consumidora de biodiesel, consumindo $21 \%$ do total europeu, seguida da Alemanha (18\%) e da Itália (11\%). A Figura 6 mostra a evolução do consumo de biodiesel no transporte na UE.

No que concerne ao comércio internacional de biodiesel, cumpre dizer que as exportações, iniciadas em 2008, permaneceram praticamente constantes até 2012, e tiveram pequeno aumento em 2013.

Figura 4. Exportação e importação brasileiras de biodiesel

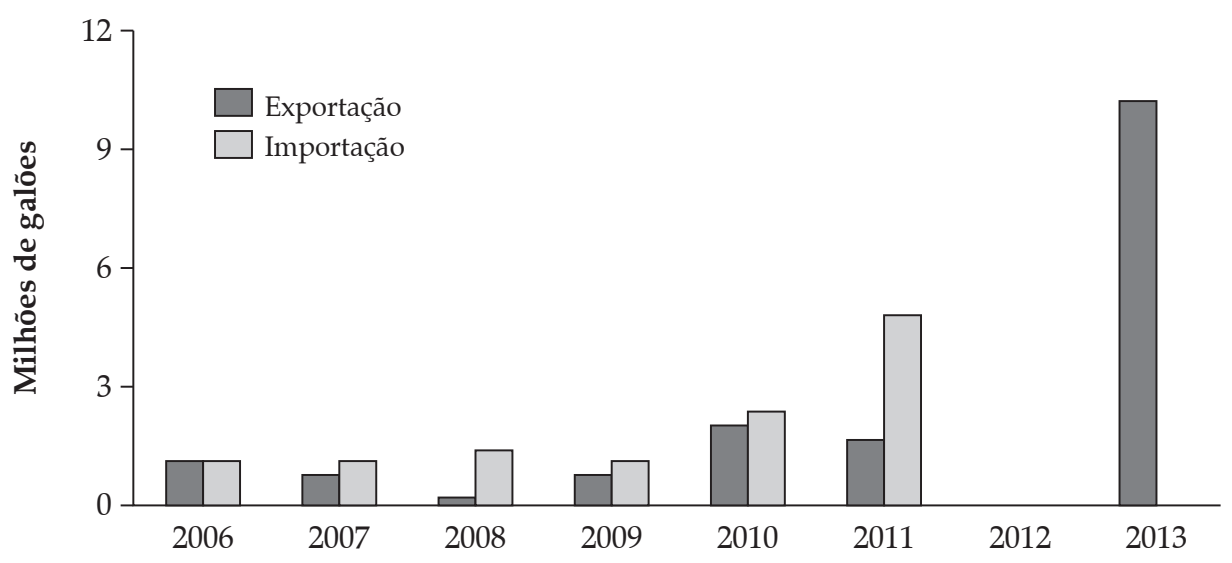

Fonte: Beckman (2015). 
Figura 5. Produção de biodiesel na União Europeia (EU-27): 2002-2013 (mil toneladas)

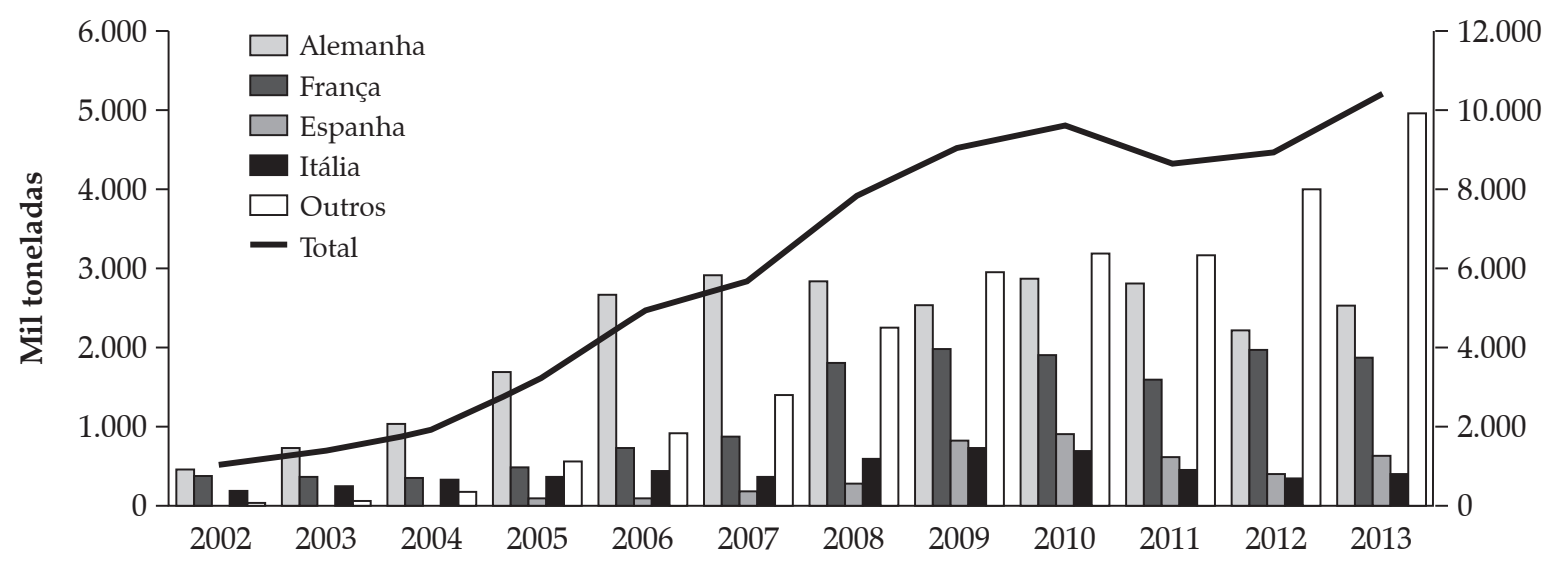

Fonte: EBB (2015).

Figura 6. Evolução do consumo de biodiesel no setor de transporte na UE-27

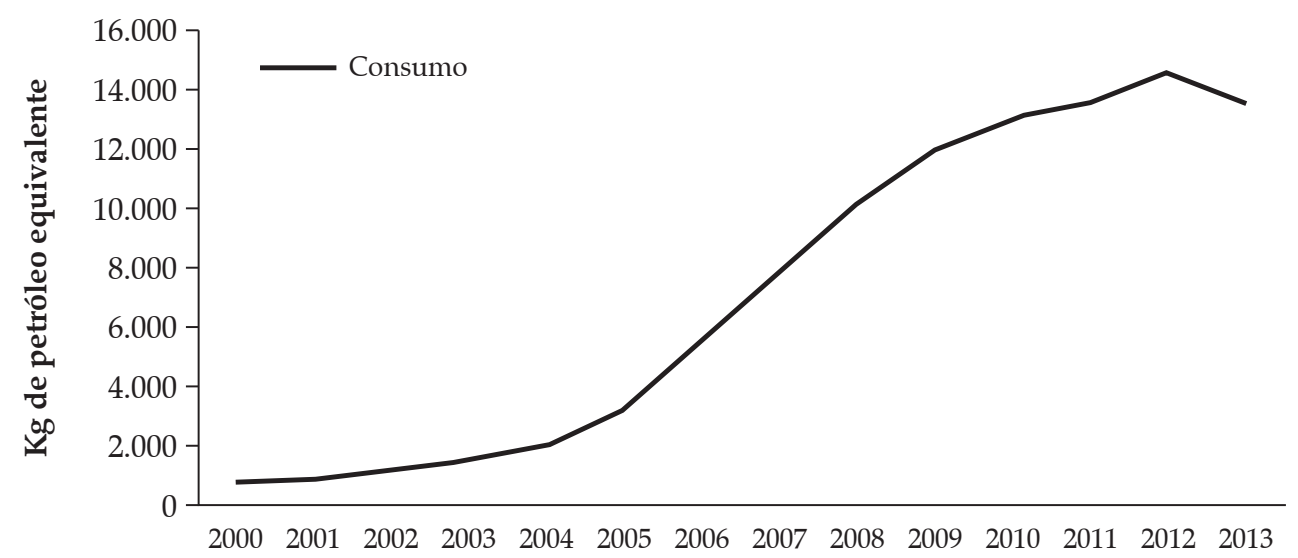

Fonte: EurObserv'ER $(2010 ; 2014)$.

Figura 7. Exportação e importação de biodiesel na UE

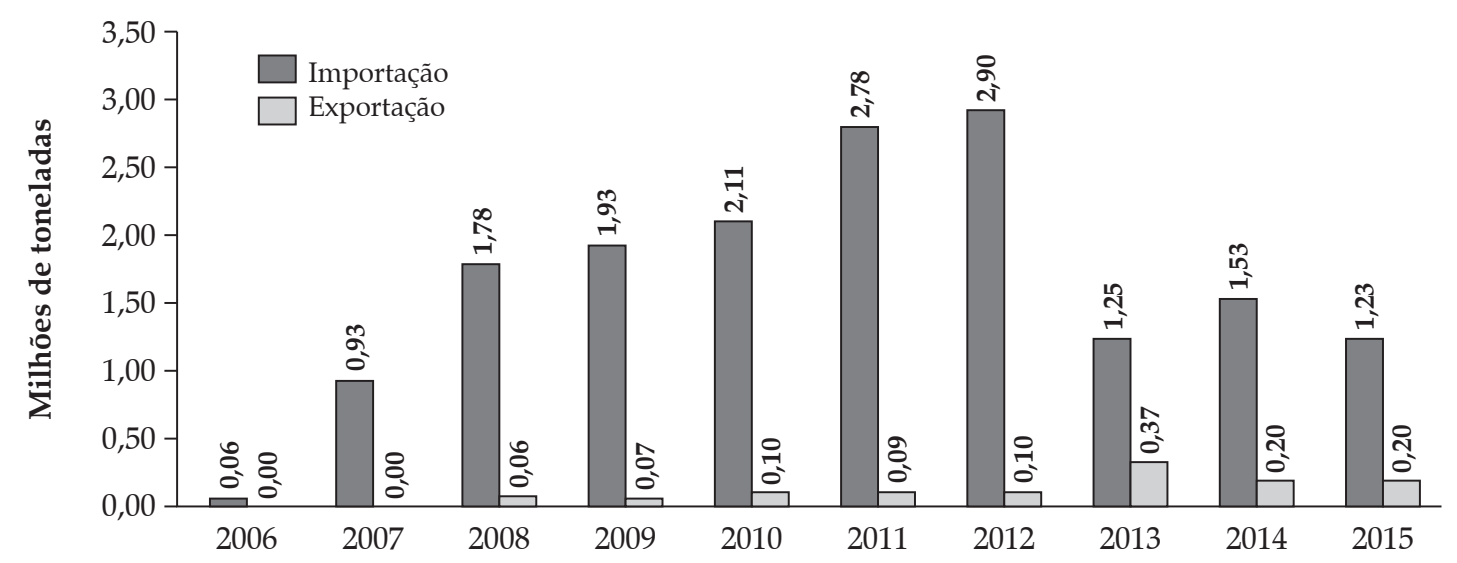

Fonte: United States Department of Agriculture - USDA (2014). 
Em relação às importações, apresentaram contínuo crescimento até 2012, tendo redução de 57\% em 2013, como mostra a Figura 7.

Os principais países europeus importadores de biodiesel são Holanda, Espanha, Itália e Reino Unido, enquanto os principais países exportadores para a União Europeia são os Estados Unidos, a Argentina e a Indonésia.

\section{Metodologia: análise fatorial por componentes principais}

A Análise Fatorial (Factor Analysis - FA) é uma técnica de estatística multivariada utilizada para análise de variabilidade comum entre um conjunto de variáveis. Mingoti (2005, p. 99) afirma que o principal objetivo da análise fatorial é "descrever a variabilidade original do vetor aleatório $X$, em termos de um número menor $m$ de variáveis aleatórias, chamadas de fatores comuns e que estão relacionadas com o vetor original $X$ através de um modelo linear". Ou seja, a FA analisa a correlação existente entre as variáveis de forma a agrupá-las em um número menor de variáveis (fatores). Normalmente, busca-se a redução do número de variáveis por meio dos fatores, porém, estes podem ser tantos quantas forem as variáveis originais caso estas variem independentemente umas das outras (CORRAR et al., 2014).

Os fatores são estimados por uma combinação linear das variáveis originais da seguinte forma:

$$
F_{j}=\omega_{j 1} X_{1}+\omega_{j 2} X_{2}+\omega_{j 3} X_{3}+\ldots+\omega_{j i} X_{i}
$$

Em que: $F_{j}$ são os fatores não correlacionados; $\omega_{j i}$ é o vetor dos coeficientes dos escores fatoriais; $X_{i}$ são as variáveis originais; e $\omega_{j i} X_{i}$ são os escores fatoriais.

O grau de correlação ente as variáveis originais e os fatores é chamado de cargas fatoriais, e seu quadrado representa o percentual de variação de uma variável, que é explicado pelo fator ao qual ela está relacionada. As variações em uma variável podem ser explicadas por meio de um conjunto de fatores, como segue (CORRAR et al., 2014):

$$
Z_{i}=l_{i 1} F_{1}+l_{i 2} F_{2}+\ldots+l_{i m} F_{m}+\varepsilon_{i}
$$

Em que: $Z_{i}$ são as variáveis padronizadas; $l_{i}$ representam as cargas fatoriais; $F_{j}$ são os fatores não relacionados entre si; e $\varepsilon_{i}$ é um erro que representa a parcela de variação exclusiva da variável $i$, com $i=1,2, \ldots, m$. Dessa forma, o modelo básico de análise fatorial, considerando uma combinação linear, tem a seguinte estrutura (MINGOTI, 2005):

$$
\begin{aligned}
& Z_{1}=l_{11} F_{1}+l_{12} F_{2}+\ldots+l_{1 m} F_{m}+\varepsilon_{1} \\
& Z_{2}=l_{21} F_{1}+l_{22} F_{2}+\ldots+l_{2 m} F_{m}+\varepsilon_{2} \\
& \begin{array}{llllll}
\vdots & \vdots & \vdots & \vdots & \vdots & \vdots
\end{array} \\
& Z_{p}=l_{p 1} F_{1}+l_{p 2} F_{2}+\ldots+l_{p m} F_{m}+\varepsilon_{p}
\end{aligned}
$$

Para estimar o modelo é necessário assumir algumas suposições, quais sejam: (1) todos os fatores possuem médias iguais a zero; (2) todos os fatores são não correlacionados e têm variâncias iguais a unidade; (3) todos os erros possuem médias iguais a zero; (4) os erros são não correlacionados e não necessariamente têm a mesma variância e (5) os erros e os fatores são independentes, ou seja, representam fontes distintas de variação (MINGOTI, 2005).

Quando o modelo de análise fatorial apresenta todas estas suposições, ele é denominado modelo fatorial ortogonal, em que a ortogonalidade diz respeito "ao fato de que os $m$ fatores são ortogonais entre si" (MINGOTI, 2005, p. 103), ou seja, os fatores são obtidos por meio da variância remanescente após a extração dos fatores antecedentes (HAIR JR. et al., 2009). Assumindo-se o modelo ortogonal, tem-se que a variância de $Z_{i}$ é decomposta em duas partes, sendo a primeira representada pela variabilidade explicada pelos fatores, chamada comunalidade; e a segunda representada pelos erros que é característica de cada uma das variáveis, denominada variância específica ou unicidade (MINGOTI, 2005).

Após a estimação do modelo de análise fatorial e extração dos fatores, alguns testes são necessários para verificar a adequabilidade do modelo. Estes testes são o teste de Kaiser-Meyer-Olkin (KMO) e o teste de esfericidade de Bartlett. O teste $\mathrm{KMO}$ é dado pela seguinte fórmula (MINGOTI, 2005):

$$
K M O=\frac{\sum_{i \neq j} R_{i j}^{2}}{\sum_{i \neq j} R_{i j}^{2}+\sum_{i \neq j} Q_{i j}^{2}}
$$

Em que: $R_{i j}$ é a correlação amostral entre as variáveis $X_{i}$ e $X_{j}$; e $Q_{i j}$ é a correlação parcial entre $X_{i}$ e $X_{j}$. O valor de $\mathrm{KMO}$ de 0,50 é o limite para a aceitabilidade, sendo que os valores abaixo de 0,50 são considerados inaceitáveis; de 0,50 a 0,59 são ruins; de 0,60 a 0,69 são razoáveis; 
de 0,70 a 0,79 são médios; de 0,80 a 0,89 são bons; e acima de 0,90 são ótimos (KAISER, 1974).

O teste de esfericidade de Bartlett mostra a significância total de todas as correlações. De acordo com Mingoti (2005) e Corrar et al. (2014), este teste mostra se a matriz de correlação é uma matriz identidade. Caso isto ocorra, a análise fatorial é inadequada para o tratamento dos dados. A estatística do teste de Bartlett é dada por (MINGOTI, 2005):

$$
T=-\left[n-\frac{1}{6}(2 p+11)\right]\left[\sum_{j=1}^{p} \ln \left(\hat{\lambda}_{i}\right)\right]
$$

Em que: $T$ é a estatística do teste; $n$ é o número de observações; $p$ é o número de variáveis; ln é a função logaritmo neperiano; e $\hat{\lambda}_{i}$ são os autovalores da matriz de correlação, $\operatorname{com} i=1,2, \ldots . p$.

Outra medida de adequação do modelo que deve ser analisada consiste na comunalidade, que representa a variabilidade explicada pelos fatores. Seu valor deve estar acima de 0,50 para que a variável seja aceitável (CORRAR et al., 2014).

Quando se utiliza questionários, outra medida de adequabilidade deve ser verificada. Mingoti (2005, p. 140) afirma que "em análises que envolvem a elaboração de indicadores através de respostas obtidas por questionários, é comum se avaliar a adequabilidade da escala utilizada através do cálculo do coeficiente alpha de Cronbach".

O alpha de Cronbach foi apresentado por Lee Joseph Cronbach em 1951 com a finalidade de validar a escala utilizada em questionários e, consequentemente, sua confiabilidade. Este coeficiente é calculado da seguinte forma (CRONBACH, 1951):

$$
\alpha=\frac{n}{n-1}\left(\frac{v_{t}-\sum_{i=1}^{n} v_{i}}{v_{t}}\right)
$$

Em que $n$ é o número de variáveis extraídas do questionário; $V i$ representa a variância de cada item; e $V t$ representa a variância total do questionário. $\mathrm{O}$ valor deste coeficiente varia entre 0 e 1 , sendo que quanto mais próximo da unidade, maior é o nível de confiabilidade da escala utilizada.

Não existe consenso na literatura quanto ao valor mínimo aceitável de alpha para validar um questionário. Fong et al. (2010) argumentam que o valor mínimo aceitável do alpha de Cronbach depende do contexto analisado, pois existem situações práticas diversas que devem ser levadas em consideração, por levar a respostas inconsistentes. Dessa forma, o valor aceitável do alpha pode variar entre 0,40 e 0,80 .

\subsection{Tratamento dos dados}

A análise fatorial foi utilizada como instrumento de tratamento dos dados obtidos por meio de questionário. Para a construção deste, foram consideradas 48 variáveis (Quadro 1). Após a identificação das variáveis, foi elaborado um questionário on-line com o intuito de saber a real importância destas variáveis para os stakeholders envolvidos no SAI biodiesel no Brasil e na União Europeia. Para tanto, optou-se por utilizar uma escala Likert de 1 a 5: (1) não importante, (2) pouco importante, (3) indiferente, (4) importante e (5) muito importante.

Quadro 1. Variáveis e suas referências

\begin{tabular}{|l|l|}
\hline \multicolumn{1}{|c|}{ Variantes } & \multicolumn{1}{|c|}{ Referências } \\
\hline $\begin{array}{l}\text { X1 (mecan): Grau de mecanização e produtividade da produção de ma- } \\
\text { téria-prima agropecuária }\end{array}$ & Khalil (2006) \\
\hline $\begin{array}{l}\text { X2 (assistec): Assistência técnica aos produtos de matéria-prima agrope- } \\
\text { cuária }\end{array}$ & Brasil (2005), Okada (2008) \\
\hline X3 (ofertbio): Garantia de produção e oferta constante de biodiesel & Olivério (2006) \\
\hline $\begin{array}{l}\text { X4 (diversif): Diversificação do tipo de matéria-prima usada na produção } \\
\text { de biodiesel }\end{array}$ & Demirbas (2009), Chagas (2012) \\
\hline $\begin{array}{l}\text { X5 (agrifan): Aquisição de matéria-prima proveniente da agricultura fa- } \\
\text { miliar e/ou pequenos agricultores }\end{array}$ & Brasil (2005) \\
\hline $\begin{array}{l}\text { X6 (bx): Percentual mínimo de mistura de biodiesel no óleo diesel } \\
\text { X7 (inovtec): Desenvolvimento de inovações de processo e produto }\end{array}$ & $\begin{array}{l}\text { Brasil (2005), Olivério (2006), Krause (2008), Zezza } \\
\text { (2008), European Comission (2009a), Brasil (2014) }\end{array}$ \\
\hline
\end{tabular}




\begin{tabular}{|c|c|}
\hline Variantes & Referências \\
\hline $\begin{array}{l}\text { X8 (gee): Desenvolvimento de tecnologias que reduzam a emissão de ga- } \\
\text { ses de efeito estufa e impactos ambientais negativos durante o processo } \\
\text { de produção de biodiesel }\end{array}$ & Amigun et al (2011) \\
\hline $\begin{array}{l}\text { X9 (agua): Desenvolvimento de tecnologias que reduzam o desperdício } \\
\text { de água durante o processo de produção de biodiesel }\end{array}$ & Amigun et al (2011) \\
\hline $\begin{array}{l}\text { X10 (residuos): Desenvolvimento de tecnologias que reduzam a geração } \\
\text { de resíduos durante o processo de produção de biodísel }\end{array}$ & Amigun et al. (2011) \\
\hline $\begin{array}{l}\text { X11 (tecavan): Uso de tecnologia avançada no processo de produção de } \\
\text { biodiesel }\end{array}$ & $\begin{array}{l}\text { Olivério (2006), Zezza (2008), European Comissions } \\
\text { (2009a), Demirbas (201), Chagas (2012) }\end{array}$ \\
\hline $\begin{array}{l}\text { X12 (patente): Criação de patentes de novos processos de produção de } \\
\text { biodiesel }\end{array}$ & OCDE (2004) \\
\hline X13 (rh): Garantia da qualidade e produtividade dos recursos humanos & Chagas (2012) \\
\hline $\begin{array}{l}\text { X14 (logistica): Desenvolvimento de capacidade de armazenamentos e } \\
\text { resolução de problemas relacionados ao transporte }\end{array}$ & $\begin{array}{l}\text { Khalil (2006), Chagas (2012), Santos et al. (2013), Cai- } \\
\text { xeta Filho (2014) }\end{array}$ \\
\hline $\begin{array}{l}\text { X15 (parcforn): Estabelecimento de parcerias com fornecedores de ma- } \\
\text { téria-prima }\end{array}$ & $\begin{array}{l}\text { Brasil (2005), Prates et al. (2007), Rosillo-Calle et al. } \\
\text { (2009), Prado, Vieira (2010) }\end{array}$ \\
\hline X16 (pacinstp): Estabelecimento de parcerias com instituições de pesquisa & McCormick e Kaberger (2005) \\
\hline X17 (vertical): Estabelecimento de vínculos de verticalização & Quintella et al. (2009), Imasato (2010), Rico (2013) \\
\hline X18 (marketing): Promoção do marketing industrial & Chagas (2012) \\
\hline $\begin{array}{l}\text { X19 (bloco): Influência do bloco econômico Mercosul (para o Brasil) ou } \\
\text { União Europeia (para EU) }\end{array}$ & Okada (2008) \\
\hline X20 (tribut): Tributação vigente sobre biodiesel & Zezza (2008), Chagas (2012) \\
\hline X21 (legisl): Legislação vigente sobre biodiesel & Chagas (2012) \\
\hline X22 (certif): Aquisição de certificado para o biodiesel & Brasil (2005) \\
\hline $\begin{array}{l}\text { X23(alfandega): Barreiras alfandegárias para compra e venda de maté- } \\
\text { rias-primas e/ou biodiesel }\end{array}$ & $\begin{array}{l}\text { Okada (2008), Zezza (2008), Amigun et al. (2011), Car- } \\
\text { doso, Galante (2014) }\end{array}$ \\
\hline X24 (pd): Investimento em Pesquisa e Desenvolvimento & Zezza (2008), Chagas (2012) \\
\hline X25 (instpes): Obter apoio das instituições de pesquisa & Chagas (2012), Pedroti (2013) \\
\hline X26 (instfinanc): Obter apoio das instituições financeiras & Chagas (2012) \\
\hline X27(coop): Organizações de apoio (cooperativas agrícolas) & Lapassade (1985) \\
\hline X28 (consum): Aceitação pelo consumidor & Khalil (2006), Chagas (2012) \\
\hline X29 (univ): Obter apoio das universidades & Chagas (2012) \\
\hline X30 (tecprod): Melhoramento das técnicas de produção & Krause (2008) \\
\hline X31 (fisicquim): Realização de análise físico-química do biodiesel & Krause (2008) \\
\hline X32 (processo): Investir no aperfeiçoamento de processo & Krause (2008), Chagas (2012) \\
\hline X33 (desproduto): Investir no desenvolvimento de produto & Krause (2008), Chagas (2012) \\
\hline X34 (precobio): Garantia de preço competitivo de venda de biodiesel & Olivério (2006) \\
\hline X35 (custobio): Garantia de custo competitivo de produção e biodiesel & \begin{tabular}{|l}
$\begin{array}{l}\text { Demirbas (2007), European Comission (2009a), } \\
\text { Chagas (2012) }\end{array}$ \\
\end{tabular} \\
\hline X36 (qualimp): Garantia de qualidade de matéria-prima & Khalil (2006), European Commission (2009a) \\
\hline X37 (qualibio): Garantia de qualidade do biodiesel & Brasil (2005), Olivério (2006) \\
\hline X38 (subsidmp): Subsídio à produção de matéroa-prima & Zezza (2008), Demirbas (2009), Chagas (2012) \\
\hline X39 (subsidio): Subsídio à produção de biodiesel & Zezza (2008), Chagas (2012) \\
\hline X40 (infraest): Investimento em infraestrutura & Demirbas (2007), Chagas (2012) \\
\hline X41 (polsoc): Influência das políticas sociais & Brasil (2005) \\
\hline X42 (polecon): Influência das políticas econômicas & Zezza (2008) \\
\hline X43 (polamb): Influência das políticas ambientais & Zezza (2008), European Commission (2009b) \\
\hline X44 (poltarif): Influência das políticas tarifárias & Zezza (2008), Chagas (2012) \\
\hline $\begin{array}{l}\text { X45 (polnac): Influência das políticas nacionais relacionadas aos biocom- } \\
\text { bustíveis }\end{array}$ & Oliveira (2010), Chagas (2012) \\
\hline $\begin{array}{l}\text { X46 (polintern): Influência das políticas internacionais aos biocombus- } \\
\text { tíveis }\end{array}$ & $\begin{array}{l}\text { Zezza (2008), European Commission (2009a; 2009b), } \\
\text { Chagas (2012) }\end{array}$ \\
\hline X47 (sindic): Sindicato dos Trabalhadores & Oliveira (2010), Pedrovi (2013) \\
\hline X48 (assbio): Associações que representam as usinas de biodiesel & Oliveira (2010) \\
\hline
\end{tabular}

Fonte: Elaboração própria. 
Os questionários foram enviados via e-mail para 16 Unidades Federativas do Brasil (112 questionários) ${ }^{5}$ e para 20 países da União Europeia (199 questionários) ${ }^{6}$, entre maio e junho de 2015. A amostragem foi baseada na disponibilidade dos contatos, procurando diversificar os respondentes dentro das Unidades Federativas do Brasil e dentro dos países da União Europeia.

Foram obtidas 81 respostas válidas, portanto, devido ao baixo número de respostas vis à vis o número de variáveis, estas foram agrupadas em 13 grupos (Quadro 2).

Criou-se um índice para cada grupo por meio da análise fatorial e, posteriormente, estes 13 índices foram utilizados como variáveis, mantendo a representatividade das variáveis originais, conforme Mingoti (2005), Hair Jr. et al. (2009) e Corrar et al. (2014). O índice foi calculado da seguinte forma:

$$
I_{i}=\frac{\sum_{i=1}^{N}\left(w_{i} f_{i}\right)}{\sum_{i=1}^{N} w_{i}}
$$

Em que $I_{i}$ é o valor do índice construído para representar um grupo de variáveis; $N$ é o número de fatores; $w_{i}$ são a proporção de variância explicada por cada fator; e $f_{i}$ são os escores fatoriais.

Cabe ressaltar que o uso da análise fatorial para interpretação de dados obtidos por meio de questionário, usando ou não escala Likert, é utilizada tanto pela literatura nacional quanto internacional. Podem ser citados os trabalhos de Guimarães et al. (2009), Hof (2012), Guimarães Jr. et al. (2013), Santos et al. (2013), Bagheri e Bordbar (2014), Giampietri (2016), Weissenburger-Moser et al. (2016) e Cardoso et al. (2017), entre outros.

\section{Resultados e discussão}

Os resultados dos testes de adequabilidade do modelo de análise fatorial tanto para o Brasil quanto para a União Europeia foram satisfatórios, conforme

5. Amazonas, Bahia, Ceará, Distrito Federal, Goiás, Mato Grosso, Mato Grosso do Sul, Minas Gerais, Paraíba, Paraná, Rio de Janeiro, Rio Grande do Sul, Rondônia, Santa Catarina, São Paulo e Tocantins.

6. Alemanha, Áustria, Bélgica, Bulgária, Chipre, Dinamarca, Eslováquia, Espanha, Finlândia, França, Grécia, Holanda, Irlanda, Itália, Polônia, Portugal, Reino Unido, República Checa, Romênia e Suécia.
Kaiser (1974), Mingoti (2005), Fong et al. (2010) e Corrar et al. (2014). Tal adequabilidade pode ser comprovada por meio dos valores do teste $\mathrm{KMO}$, do teste de Bartlett e do alpha de Cronbach, expostos na Tabela 1.

O valor de KMO maior do que 0,50 é aceitável por Kaiser (1974) e Corrar et al. (2014), deste modo os fatores encontrados conseguem representar as variações dos dados originais, explicando razoavelmente tal variação, isto é, os valores de KMO encontrados para o Brasil e para a União Europeia são considerados adequados e suficientemente bons para a realização da análise fatorial.

A significância dos valores do teste de Bartlett também mostra que a aplicação da análise fatorial para o tratamento dos dados é adequada. O teste de Bartlett foi significante a $1 \%(\mathrm{p}$-valor $=0,000)$ para o Brasil e a $5 \%$ (p-valor $=0,034)$ para a União Europeia, o que está de acordo com os pré-requisitos para a análise fatorial, conforme Mingoti (2005) e Hair Jr. et al. (2009).

$\mathrm{O}$ alpha de Cronbach mostra que a escala utilizada no questionário para a obtenção das respostas foi adequada, conforme Fong et al. (2010), uma vez que o valor de alpha em ambos os contextos encontra-se dentro do intervalo de 0,40 a 0,80 .

Uma vez satisfeitas todas as condições de adequabilidade do uso da análise fatorial, esta foi realizada por meio do método de componentes principais, pelo software Statistical Package for the Social Sciences (SPSS), versão 17. Considerando o critério do autovalor, que consiste na escolha dos fatores que possuem autovalores maiores do que a unidade, foram obtidos quatro componentes que explicam $60,2 \%$ da variação total para o Brasil (Tabela 2) e dois componentes que explicam $53,9 \%$ da variação total para a União Europeia (Tabela 3).

No que concerne aos componentes resultantes da análise fatorial, estes estão expostos na Tabela 4 para o Brasil e na Tabela 5 para a União Europeia, junto as suas cargas fatoriais e comunalidades após a rotação ortogonal varimax. Embora a escolha do percentual das cargas fatoriais utilizado seja relativamente subjetiva, optou-se por considerar neste trabalho as cargas fatoriais acima de 0,50 para a interpretação dos índices mais fortemente relacionados a cada fator.

Pode-se observar na Tabela 4 que os valores das comunalidades são todos acima de 0,50, o que significa que os índices têm sua variabilidade representada pelos componentes obtidos (MINGOTI, 2005; HAIR JR. et al., 2009; CORRAR et al., 2014). 
Quadro 2. Grupos das variáveis

\begin{tabular}{|c|c|}
\hline Grupos & Variáveis \\
\hline Y1 (ASSIST - assistência ao produtor de matéria-prima) & $\mathrm{X} 1$ (mecan); X2 (assistec) \\
\hline $\begin{array}{l}\text { Y2 (DIV_AQUI_GAR - diversificação, aquisição da agricultura familiar/ } \\
\text { pequeno produtor e garantia de oferta) }\end{array}$ & X3 (ofertbio); X4 (diversif); X5 (agrifam) \\
\hline Y3 (TECNOL_PROD - tecnologias de produção) & X7 (inovtec); X8(gee); 9 (água); X10 (residuos); X11 (tecavan) \\
\hline Y4 (ESTRAT - estratégias de crescimento) & $\begin{array}{l}\text { X14 (logistica); X15 (parcforn); X16 (parcinstp); X17 (vertcal); X18 (ma- } \\
\text { rketing) }\end{array}$ \\
\hline Y5 (DIFER_BIO - diferenciação na produção de biodiesel) & X30 (tecprod); X31 (fisicquin); X32 (processo); X33 (desproduto) \\
\hline Y6 (DIFER_USINA - diferenciação na usina) & X12 (patente); X22 (certific); X24 (pd); X25 (instpesq) \\
\hline Y7 (INCENT - incentivos à produção de biodiesel) & X6 (bx); X38 (subsidmp); X39 (subsidbio); X40 (infraest) \\
\hline Y8 (POL_ESP - políticas nacionais específicas) & X41 (polsoc); X42 (polecon); X43 (polamb) \\
\hline Y9 (POL_GER - políticas gerais de biocombustíveis) & X45 (polnac); X46 (polintern) \\
\hline Y10 (SINDASS - sindicatos e associações) & X47 (sindic); X48 (assbio) \\
\hline Y11 (TRIB_COMINT - tributos e comércio internacional) & X19 (bloco); X20 (tribut); X21 (legisl); X23 (alfandega); X44 (poltarif) \\
\hline Y12 (COMPET - competitividade da usina) & X13 (rh); X34 (precobio); X35 (custobio); X36 (qualimp); X37 (qualibio) \\
\hline Y13 (ORG - organizações de apoio) & X26 (instfinanc); X27 (coop); X28 (consum); X29 (univ) \\
\hline
\end{tabular}

Fonte: Elaboração própria.

Tabela 1. Resultados dos testes KMO e Bartlett e alpha de Cronbach

\begin{tabular}{llcc}
\hline & & Brasil & União Europeia \\
\hline KMO & 0,67 & 0,61 \\
\hline \multirow{2}{*}{ Teste de esfericidade de Bartlett } & $\chi^{2}$ & 93.390 & 19.558 \\
& p-valor & 0,000 & 0,034 \\
\hline Alpha Cronbach & & 0,677 & 0,402 \\
\hline
\end{tabular}

Fonte: Resultados da pesquisa.

Tabela 2. Número de componentes obtidos para o Brasil e suas variâncias

\begin{tabular}{cccc}
\hline Componentes $(\mathbf{C P})$ & Autovalor & Variância explicada pelo CP (\%) & Variância cumulativa (\%) \\
\hline CP1 & $\mathbf{2 , 4 1 5}$ & 17,695 & 17,695 \\
CP2 & $\mathbf{1 , 3 8 8}$ & 16,391 & 34,086 \\
CP3 & $\mathbf{1 , 1 4 1}$ & 14,124 & 48,210 \\
CP4 & $\mathbf{1 , 0 7 8}$ & 12,007 & $\mathbf{6 0 , 2 1 7}$ \\
\hline
\end{tabular}

Fonte: Resultados da pesquisa.

Tabela 3. Número de componentes obtidos para a União Europeia e suas variâncias

\begin{tabular}{cccc}
\hline Componentes (CP) & Autovalor & Variância explicada pelo CP (\%) & Variância cumulativa (\%) \\
\hline CP1 & $\mathbf{1 , 6 1 3}$ & 26,950 & 26,950 \\
CP2 & $\mathbf{1 , 0 8 0}$ & 26,919 & $\mathbf{5 3 , 8 6 9}$ \\
\hline
\end{tabular}

Fonte: Resultados da pesquisa.

Tabela 4. Componentes, cargas fatoriais e comunalidades para o caso brasileiro

\begin{tabular}{cccccc}
\hline Índices & $\mathbf{C P 1}$ & $\mathbf{C P 2}$ & $\mathbf{C P 3}$ & $\mathbf{C P 4}$ & Comunalidades \\
\hline Y4 & $\mathbf{0 , 7 9 3}$ & 0,134 & $-0,123$ & $-0,220$ & 0,711 \\
Y11 & $\mathbf{0 , 6 8 1}$ & $-0,251$ & 0,220 & 0,230 & 0,628 \\
Y12 & $\mathbf{0 , 6 1 6}$ & 0,520 & 0,184 & 0,067 & 0,688 \\
Y10 & $-0,150$ & $\mathbf{0 , 7 6 3}$ & 0,062 & 0,025 & 0,609 \\
Y6 & 0,272 & $\mathbf{0 , 6 8 4}$ & 0,021 & 0,068 & 0,547 \\
Y7 & 0,118 & $-0,051$ & $\mathbf{0 , 7 9 4}$ & $-0,122$ & 0,661 \\
Y9 & $-0,006$ & 0,161 & $\mathbf{0 , 6 6 7}$ & 0,186 & 0,506 \\
Y2 & 0,141 & 0,203 & 0,347 & $\mathbf{- 0 , 6 0 2}$ & 0,544 \\
Y3 & 0,394 & 0,169 & 0,159 & $\mathbf{0 , 5 9 1}$ & 0,558 \\
Y8 & $-0,108$ & 0,375 & 0,300 & $\mathbf{0 , 5 7 3}$ & 0,570 \\
\hline
\end{tabular}

Fonte: Resultados da pesquisa. 
Em relação aos componentes, o componente 1 (CP1), composto pelos índices Y4 (estratégias de crescimento), Y11 (tributos e comércio internacional) e Y12 (competitividade da usina), pode ser nominado Gestão Estratégica e Condições de Mercado. Este componente tem os indicadores com maiores cargas fatoriais e maior percentual de variância explicada $(17,7 \%)$. Quanto maior o escore fatorial deste componente, maior é a importância da gestão estratégica e condições de mercado para a coordenação do SAI biodiesel no Brasil. Observa-se que as cargas fatoriais têm todas o mesmo sinal (positivo), o que implica dizer que todos os índices caminham na mesma direção em termos de importância, isto é, quando um tende a aumentar o grau de importância, os demais também seguem o mesmo movimento.

Com efeito, as incertezas presentes nas usinas de biodiesel quanto à qualidade da matéria-prima adquirida, do biodiesel produzido e dos recursos humanos, bem como quanto ao custo de produção e ao preço de venda (estabelecido pelos leilões) fazem com que as usinas busquem estratégias que visem reduzir tais incertezas, como a verticalização e parcerias com fornecedores e instituições de pesquisa (McCORMICK e KÅBERGEN, 2005; QUINTELLA et al., 2009; IMASATO, 2010; RICO, 2013). De fato, Williamson (1985) e Zylbersztajn (1995) afirmam que as firmas devem buscar estruturas de governança (mercado, contratos, verticalização, leilões etc.) que melhor se adequem às características do produto, neste caso, do biodiesel, considerando a especificidade do ativo e a frequência das transações.

Como a produção de biodiesel exige diversidade nas matérias-primas, sua especificidade pode ser locacional, já que as usinas devem adquirir parte de sua matéria-prima da agricultura familiar de determinada região. Além disso, como a produção brasileira ainda é pequena em relação à capacidade produtiva e tendência de expansão do consumo, os leilões se fazem necessários mais de uma vez ao mês. Dessa forma, a busca pela parceria com fornecedores de matéria-prima e com as instituições de pesquisa, bem como pela verticalização podem reduzir as incertezas da qualidade tanto da matéria-prima quanto do biodiesel produzido, e do custo de produção e preço de venda (PRATES et al., 2007; ROSILLO-CALLE et al., 2009; PRADO e VIEIRA, 2010).

Além disso, as barreiras ao comércio internacional, criadas pela legislação vigente tanto no contexto nacional quanto internacional (caso da exportação de soja para a União Europeia, por exemplo - CARDOSO e GALANTE, 2014), aumentam ainda mais tais incertezas, fazendo com que as usinas de biodiesel procurem maior promoção de marketing industrial para provar que sua produção é sustentável e atende à legislação vigente, e alguma forma de verticalização para garantirem a qualidade da matéria-prima e do biodiesel e o maior controle sobre os custos de produção (DEMIRBAS, 2009; OLIVEIRA, 2010).

O segundo componente (CP2), constituído pelos índices Y10 (sindicatos e associações) e Y6 (diferenciação na usina), pode ser nominado Estratégias de Diferenciação e Crescimento. Este fator possui 16,4\% da variância explicada e mostra que a presença dos sindicatos dos trabalhadores e das associações que representam as usinas de biodiesel estão relacionadas às estratégias de diferenciação das usinas, como criação de patentes, obtenção de certificação para o biodiesel, investimentos em P\&D e a busca de apoio das instituições de pesquisa. Como as cargas fatoriais possuem o mesmo sinal (positivo), pode-se dizer que, quando aumenta o grau de importância dos sindicatos e das associações, o grau das estratégias de diferenciação das usinas também aumenta e vice-versa.

Sobre isto, pode-se dizer que os sindicatos e as associações no sistema agroindustrial do biodiesel atuam no sentido de representar corporativamente as usinas perante as políticas públicas, garantindo seus direitos. As associações facilitam o investimento conjunto em P\&D dentro das usinas e a busca ao apoio das instituições de pesquisa, à certificação e à criação de patentes (OCDE, 2004; QUINTELLA et al., 2009; PEDROTI, 2013). Esta relação é claramente observada no ambiente organizacional de um sistema agroindustrial, em que tal afinidade está associada ao papel das organizações de apoio no funcionamento do sistema (LAPASSADE, 1985; NORTH, 1992; ZYLBERSZTAJN, 1995; FARINA et al., 1997; GREIF e LAITIN, 2004).

O terceiro componente (CP3), composto por Y7 (incentivos à produção de biodiesel) e Y9 (políticas específicas voltadas aos biocombustíveis), que explica $14,1 \%$ da variância total, pode ser nominado Ambiente Institucional. Este componente está fortemente relacionado com as políticas nacionais e internacionais voltadas à produção e uso de biodiesel, incluindo os mandatos de mistura de biodiesel no óleo diesel (BX), subsídios à produção de matérias-primas e de biodie- 
sel, e investimentos em infraestrutura. Ambos os índices possuem cargas fatoriais positivas, o que permite dizer que seus graus de importância caminham na mesma direção.

As políticas voltadas aos biocombustíveis visam ao desenvolvimento destes para garantir a segurança energética, redução da dependência do petróleo e redução da emissão de gases de efeito estufa. Contudo, o desenvolvimento dos biocombustíveis não é viável sem o apoio público (ZEZZA, 2008). Neste sentido, o Brasil, por meio do Programa Nacional de Produção e Uso de Biodiesel (PNPB), impulsiona a produção de biodiesel através de estímulos às usinas (Selo Combustível Social) e aos produtores de matéria-prima (BRASIL, 2012). Além disso, a Lei n. 13.033/2014 estabelece o mandato mínimo de B7, o que também impulsiona o desenvolvimento do SAI biodiesel. De acordo com Olivério (2006) e Chagas (2012), o sistema agroindustrial do biodiesel ainda possui logística deficitária, o que necessita de maior intervenção por parte do Governo, ou seja, políticas mais adequadas ao setor?. Neste sentido, quanto mais as políticas específicas aos biocombustíveis focarem o desenvolvimento do biodiesel no Brasil, mais incentivos terá a produção deste biocombustível, e melhorias serão feitas na logística.

Como o SAI biodiesel é um sistema mutável, suas instituições devem acompanhar o seu desenvolvimento, isto é, na medida em que há avanços na produção de biodiesel, mudanças institucionais são necessárias para que haja maior incentivo ao uso e à comercialização deste biocombustível (COMMONS, 1931; WILLIAMSON, 2000; NORTH, 2005). Esta colocação pode ser corroborada com uma das proposições que caracterizam a mudança institucional de North (2005), que argumenta que as organizações, ao receberem incentivos, apresentam um desempenho que pode resultar em esforços para a mudança institucional. Fato que foi observado no Brasil quando, em 2005, a Lei n. 11.097 propôs um mandato de B5 a ser cumprido até 2013, mas com o desempenho favorável do setor ao receber incentivos (Selo Combustível Social para as usinas e garantia de venda de parte da produção para os agricultores familiares) para o cumprimento do mandato em questão, houve a necessidade

7. Conforme Caixeta Filho (2014), a logística deficitária não é uma peculiaridade do biodiesel. Esta deficiência se encontra presente em todos os setores da economia brasileira, principalmente no agronegócio. de uma mudança institucional que fez com que a meta do mandato de B5 fosse antecipada para 2010.

Por fim, o quarto componente (CP4), constituído pelos índices Y2 (diversificação, aquisição da agricultura familiar/pequeno produtor e garantia de oferta), Y3 (tecnologias de produção) e Y8 (políticas nacionais gerais), que explica $12,0 \%$ da variância total, pode ser nominado Diversificação, Aquisição e Garantia, Tecnologias e Políticas. Este fator está fortemente relacionado com os tipos de tecnologias utilizadas na produção de biodiesel e com as políticas econômica, social e ambiental. As cargas fatoriais dos índices Y3 e Y8 mostram que eles caminham na mesma direção. Porém, o sinal negativo da carga fatorial do índice Y2 significa que o grau de importância da diversificação da matéria-prima utilizada na produção de biodiesel, da aquisição de matéria-prima da agricultura familiar e da garantia de produção e oferta constante de biodiesel segue sentido oposto ao dos tipos de tecnologias utilizadas na produção e das políticas econômicas, sociais e ambientais estabelecidas pelo País.

Esta peculiaridade retratada pelo componente CP4 (sinais opostos) merece uma atenção maior. Santos et al. (2013) explicam que o biodiesel de primeira geração, aquele de culturas alimentares, ainda é o mais utilizado no Brasil e utiliza tecnologias básicas e intermediárias. Neste contexto, a diversificação da matéria-prima em busca do uso de fontes não alimentares (como resíduos provenientes das estações de tratamento de esgoto, algas, efluentes de laticínios etc.), demanda a utilização de tecnologias mais avançadas (DEMIRBAS, 2010), o que não inclui evidentemente a agricultura familiar. Dessa forma, as políticas gerais que visam o desenvolvimento socioeconômico e ambiental influenciam na busca pela produção sustentável de biodiesel (DEMIRBAS, 2007; AMIGUN et al., 2011), o que implica na utilização de culturas não alimentares e, portanto, de tecnologias avançadas.

Destarte, o fato de os índices Y3 e Y8 caminharem em um sentido oposto ao do índice Y2 mostra certa incompatibilidade do binômio "tecnologia e política" com "diversificação e aquisição de matéria-prima e garantia de produção". De fato, os diversos interesses vigentes no índice Y2 (diversificação, aquisição da agricultura familiar/pequeno produtor e garantia de oferta) por si só já são pontos polêmicos e, em alguns casos, incongruentes. Por exemplo, as realidades específicas de determinadas matérias-primas para a produção 
de biodiesel (como a soja, por exemplo), e suas especificidades regionais, não se adequam à produção de biodiesel advinda da agricultura familiar para estados onde o predomínio é de grandes propriedades agrícolas, como no Centro-Oeste (OKADA, 2008).

As especificidades regionais, junto às características das potenciais matérias-primas devem ser levadas em consideração na formulação de políticas públicas, uma vez que cada matéria-prima tem peculiaridades que são denominadas especificidade de ativos. Neste caso, a especificidade é a de ativos dedicados, pois, para a produção de biodiesel de segunda, terceira e quarta gerações é necessário investimentos em tecnologias que não são adequadas para a produção de biodiesel de primeira geração (FARINA et al., 1997; DEMIRBAS, 2010).

Dessa forma, os avanços nas políticas voltadas ao desenvolvimento sustentável do País, que propõem o uso de fontes não alimentícias para a produção de biodiesel, marginalizariam os agricultores familiares em função da especificidade das matérias-primas utilizadas.

Após apresentar o cenário brasileiro, a Tabela 5 mostra os componentes obtidos para a União Europeia. As comunalidades encontradas para a análise europeia apresentam valores acima de 0,50, exceto para o índice Y2, confirmando a variabilidade dos índices representada pelos componentes.

Tabela 5. Componentes, cargas fatoriais e comunalidades para o caso europeu

\begin{tabular}{cccc}
\hline Índices & $\mathbf{C P 1}$ & $\mathbf{C P 2}$ & Comunalidades \\
\hline Y2 & $\mathbf{- 0 , 6 9 2}$ & $-0,121$ & 0,493 \\
Y5 & $\mathbf{0 , 6 8 6}$ & $-0,174$ & 0,500 \\
Y11 & $\mathbf{0 , 6 0 0}$ & 0,398 & 0,519 \\
Y10 & $-0,087$ & $\mathbf{0 , 7 7 6}$ & 0,610 \\
Y13 & 0,177 & $\mathbf{0 , 7 3 5}$ & 0,572 \\
\hline
\end{tabular}

Fonte: Resultados da pesquisa.

No caso da comunalidade abaixo de 0,50 (caso de Y2), Costello e Osborne (2005) afirmam que, para as análises realizadas nas ciências sociais, é comum encontrar valores para a comunalidade entre 0,4 e 0,7. Portanto, o valor de 0,493 pode ser considerado válido para esta análise.

Isto posto, pode-se considerar o índice Y2 (diversificação, aquisição da agricultura familiar/pequeno pro- dutor e garantia de oferta) na análise como parte do primeiro componente (CP1), denominado Diversificação e Garantia e Condições de Mercado, junto aos índices Y5 (diferenciação na produção de biodiesel) e Y11 (tributos e comércio internacional). Este fator foi o que apresentou maior carga fatorial e maior percentual de variância explicada $(26,95 \%)$. As cargas fatoriais com o mesmo sinal (positivo) implicam que o grau de importância destes índices segue a mesma direção, aumentando/reduzindo quando o outro aumenta/reduz. Contudo, o índice Y2 tem sinal contrário (negativo) ao dos demais deste componente, o que indica que o grau de importância da diversificação da matéria-prima utilizada na produção de biodiesel, da aquisição de matéria-prima da agricultura familiar e da garantia de produção e oferta constante de biodiesel segue sentido oposto às técnicas utilizadas para diferenciação na produção de biodiesel e às políticas voltadas para o comércio internacional e tributação do biodiesel.

Sobre isto, afirma-se que a análise físico-química do biodiesel faz-se necessária para garantir a qualidade deste biocombustível no que se refere à matéria-prima utilizada. O biodiesel solidifica-se em baixas temperaturas mais rapidamente se proveniente de óleo de canola (segunda matéria-prima mais utilizada na União Europeia) do que dos demais óleos vegetais (KRAUSE, 2008). A legislação vigente na União Europeia visa à qualidade do biodiesel de forma a garantir que sua produção não tenha grandes impactos negativos ao meio ambiente e não utilize culturas alimentares, incentivando, desta forma, as usinas a investirem no aperfeiçoamento de processo e de produto, bem como no melhoramento das técnicas de produção. Contudo, isto implica no uso de tecnologias avançadas que, por utilizarem matérias-primas não alimentícias, não envolvem os pequenos produtores (EUROPEAN COMISSION, 2009a, 2009b; DEMIRBAS, 2010).

Embora o índice Y2 tenha apresentado sinal negativo frente aos demais índices também no caso europeu, o discurso é um pouco diferente daquele do Brasil, pois a legislação europeia não prioriza os pequenos produtores, mas as matérias-primas provenientes de terrenos que não possuam alto teor de carbono e que emitam menos gases de efeito estufa do que os combustíveis fósseis (EUROPEAN COMISSION, 2009a, 2009b). Além disso, os Estados-Membros importam a maior parte da matéria-prima utilizada, e os países exportadores também devem seguir as leis europeias. Neste contexto, 
os pequenos produtores não conseguem se adaptar às exigências do mercado europeu, fazendo com que, também neste caso, eles permaneçam marginalizados no SAI biodiesel da União Europeia (DEMIRBAS, 2007).

Neste contexto, Olivério (2006) propõe que as políticas voltadas à produção e uso de biodiesel devem se adaptar à realidade do setor em cada país. Por outro lado, as organizações também devem se adaptar às mudanças no ambiente, sejam elas em termos econômicos ou políticos (BARNARD, 1938; HAYEK, 1945; ROCHA JR., 2001). Dessa forma, não somente mudanças institucionais devem ocorrer para a melhoria da coordenação do SAI biodiesel, mas as mudanças também devem vir da adequação das organizações. Afinal, Rocha Jr. (2001) afirma que a adequação das organizações às mudanças no ambiente é um dos principais problemas enfrentados por elas.

O segundo componente (CP2), composto pelos índices Y10 (sindicatos e associações) e Y13 (organizações de apoio), pode ser nominado Sindicatos, Associações e Organizações de Apoio e explica 26,92\% da variância total. O sinal das cargas fatoriais de ambos os índices mostra que ambos seguem na mesma direção, o que implica dizer que os sindicatos, as associações e as organizações de apoio possuem relação direta quanto ao grau de importância para a coordenação do SAI biodiesel na União Europeia.

Os sindicatos e as associações atuam na representação das usinas para garantir o cumprimento dos seus direitos e deveres perante a lei. Além disso, eles servem como facilitadores na busca de apoio das universidades e das instituições financeiras e na criação de um mercado consumidor (PEDROTI, 2013). Salienta-se que as associações e os sindicatos fazem parte das organizações de apoio de um sistema agroindustrial (LAPASSADE, 1985; NORTH, 1992; FARINA et al., 1997; GREIF e LAITIN, 2004).

Em ambos os contextos, brasileiro e europeu, dos índices resultantes da análise fatorial para a obtenção dos componentes principais, apenas os Y2 (diversificação, aquisição da agricultura familiar/pequeno produtor e garantia de oferta), Y10 (sindicatos e associações) e Y11 (tributos e comércio internacional) permaneceram em ambas as análises, sendo que, no caso brasileiro, cada índice encontra-se em um componente principal diverso e, no caso europeu, Y2 e Y11 pertencem ao mesmo componente. Outro fato a ser destacado nesta análise é que o índice Y11 pertence ao primeiro componente em ambos os contextos, indicando ser um elemento de maior influência na coordenação do SAI biodiesel.

É interessante ressaltar também que apenas o índice Y2 mostrou sinal negativo em ambas as análises, o que significa que a diversificação da matéria-prima utilizada na produção de biodiesel, a aquisição de matéria-prima da agricultura familiar e a garantia de produção e oferta constante de biodiesel possui grau de importância indiretamente relacionado com as demais variáveis, isto é, quando aumenta o grau de importância de Y2 reduz este grau para os demais índices e vice-versa. $\mathrm{O}$ que pode ser aferido desta análise é que, embora exista grande diversidade de potenciais matérias-primas para a produção de biodiesel, em ambos os contextos, esta diversificação não é observada no processo produtivo, seja devido à legislação que limita o uso de algumas fontes energéticas (caso de matérias-primas alimentares na União Europeia), seja devido à viabilidade técnico-econômica da produção (caso da soja no Brasil).

\section{Conclusões}

O objetivo desta pesquisa foi analisar comparativamente os principais fatores envolvidos na coordenação do SAI biodiesel no Brasil e na União Europeia, sob a perspectiva dos stakeholders deste sistema agroindustrial em ambos os contextos.

Pela análise fatorial, observou-se que os fatores semelhantes entre o SAI biodiesel no Brasil e na União Europeia são poucos, dentre os vários destacados. Aspectos como a oferta constante e estável de biodiesel, diversificação da matéria-prima e aquisição desta de pequenos agricultores ou de agricultores familiares, mostraram que, em conjunto, como um índice, seu grau de importância é inverso ao grau das demais variáveis quando agrupadas em índices. Isto implica dizer que estes aspectos perdem importância para a cordenação do SAI biodiesel quando outros ganham importância, como a tributação que envolve tanto o comércio nacional quanto o internacional, e o sindicado dos trabalhadores e as associações que representam as usinas. Neste sentido, quando aumenta a importância da tributação e as barreiras ao comércio, seja de matéria-prima, seja de biodiesel, a forma de aquisição de matéria-prima e a quantidade produzida de biodiesel ficam em segundo plano. Outrossim, quando os sindicados dos trabalhadores e as associações representativas ganham 
importância no contexto do SAI, eles agem de forma a melhorar este sistema, independente da aquisição de matéria-prima e da produção de biodiesel.

Considerando que o biodiesel proveniente de óleos vegetais ainda é o mais produzido e utilizado no mundo, embora exista grande variedade de óleos vegetais aptos à produção deste biocombustível, observa-se na prática uma concentração de determinados óleos como, por exemplo, o óleo de soja no Brasil e o óleo de palma na União Europeia. O biodiesel é considerado um ativo específico devido as suas características e, por isso, deve ser tratado de forma diferente em contextos diversos, respeitando a realidade e o interesse de cada país. No caso do Brasil, o interesse maior é pela inclusão social e desenvolvimento regional, enquanto na União Europeia o interesse é pela redução de gases de efeito estufa. Sendo assim, o desenvolvimento do SAI biodiesel deve respeitar estes interesses de modo a alcançar a produção sustentável.

A grande variedade de potenciais matérias-primas oleaginosas permite a inclusão de agricultores familiares e/ou pequenos agricultores no SAI biodiesel, porém, a busca pela redução de gases de efeito estufa incentiva o uso de tecnologias avançadas que, por sua vez, requerem o uso de matérias-primas não alimentares. Dessa forma, os agricultores familiares e os pequenos produtores seriam "marginalizados" pelo sistema (no que se refere à oferta de matéria-prima). Outrossim, o debate em torno do conflito alimentos versus biocombustíveis promove investimentos em P\&D para o uso de fontes energéticas que não sejam alimentares. Para a produção de biodiesel proveniente destas fontes é necessária a implementação de tecnologias mais avançadas.

Para ambos os contextos, os fatores semelhantes na visão dos stakeholders do SAI estão relacionados à tributação e comércio internacional, aos sindicatos dos trabalhadores e associações que representam as usinas de biodiesel, e à oferta constante e estável de biodiesel, diversificação da matéria-prima e aquisição desta de pequenos agricultores ou de agricultores familiares. Os fatores diferentes entre os dois sistemas são: (1) analisando apenas o caso brasileiro: estratégias de crescimento, competitividade das usinas, diferenciação das usinas, incentivos para a produção de biodiesel, políticas gerais sobre biocombustíveis, tecnologias de produção de biodiesel, e políticas nacionais específicas; e (2) analisando apenas o caso europeu: diferenciação na produção de biodiesel e organizações de apoio.
Isto posto, conclui-se que os resultados desta pesquisa mostraram a existência de um trade-off no que se refere ao avanço tecnológico dentro do SAI biodiesel em ambos os casos. Se, por um lado, a inclusão dos agricultores familiares e pequenos agricultores na economia é um dos fatores a serem considerados para a sustentabilidade do sistema, por outro, o desenvolvimento deste, buscando resolver o conflito alimento versus biocombustíveis, marginaliza estes produtores. Dessa forma, esta pesquisa abre espaço para pesquisas futuras, uma vez que seus resultados mostraram um trade-off que merece maior atenção, principalmente no caso brasileiro.

\section{Referências}

AGÊNCIA NACIONAL DO PETRÓLEO, GÁS NATURAL E BIOCOMBUSTÍVEIS - ANP. Biocombustíveis. Disponível em: <http://www.anp.gov. $\mathrm{br} /$ ?id=470>. Acesso em: $10 \mathrm{dez} 2015$.

AMIGUN, B., MUSANGO, J. K. e STAFFORD, W. Biofuels and sustainability in Africa. Renewable and Sustainable Energy Reviews, v. 15, p. 1360-1372, 2011.

BAGHERI, N. e BORDBAR, M. Factor analysis of agricultural mechanization challenges in Iran. Agric Eng Int: CIGR Journal, v. 16, n. 1, p. 167-172, 2014.

BARNARD, C. The function of the executive. Cambridge: Harvard University Press, 1938.

BATALHA, M. O. (Coord.). Gestão agroindustrial. Vol. 1. São Paulo: Atlas, 1997.

BECKMAN, J. Biofuel use in intenational markets: the importance of trade, EIB-144. US Department of Agriculture, Economic Research Service, Sept. 2015.

BRASIL. Ministério do Desenvolvimento Agrário. Instrução Normativa n. 1, de 05 de julho de 2005. Lex: legislação e jurisprudência, Brasília, DF, 5 jul. 2005.

Ministério do Desenvolvimento Agrário. Portaria no 60 , de 6 de setembro de 2012. Lex: legislação e jurisprudência, Brasília, DF, 6 set. 2012.

. Lei no 13.033, de 24 de setembro de 2014. Diário Oficial [da] República Federativa do Brasil, Poder Executivo, Brasília, DF, 24 set. 2014.

CAIXETA FILHO, J. V. E a tal da logística?14/11/14. RPA news. Disponível em: <http://revistarpanews.com.br/ index.php/ultimas-noticias/2113-e-a-tal-da-logisticajose-vicente-caixeta-filho > . Acesso em: 26 dez. 2015. 
CARDOSO, B. F. e GALANTE, V. A. Barreiras comerciais no comércio internacional: o caso da soja no Brasil. In: SCHNEIDER, M. B. (Org.). A inserção internacional do agronegócio brasileiro no pós-crise: a atuação da OMC, barreiras e políticas comerciais. Curitiba: LedZe, 2014.

CARDOSO, B. F., SHIKIDA, P. F. A. e FINCO, A. Development of Brazilian Biodiesel Sector from the Perspective of Stakeholders. Energies, v. 10, n. 3, p. 399413, 2017.

CHAGAS, A. L. S. Relatório estudos setoriais: biocombustíveis. Ribeirão Preto: EBC, 2012.

COMMONS, J. R. Institutional economics. The American Economic Review, v. 21, n. 4, p. 648-657, dez. 1931.

CORRAR, L. J.,PAULO, E. e DIAS FILHO, J. M. (Coords.) Análise multivariada para os cursos de administração, ciências contábeis e economia. São Paulo: Atlas, 2014.

COSTELlO, A. B. e OSBORNE, J. W. Best practices in exploratory factor analysis: four recommendations for getting the most from your analysis. Practical Assessment, Research E Evaluation, v. 10, n. 7, jul. 2005.

CRONBACH, L. J. Coefficient alpha and the internal structure of tests. Psychometrika, v. 16, n. 3, p. 297-334, 1951.

DEMIRBAS, A. Importance of biodiesel as transportation fuel. Energy Policy, v. 35, p. 4661-4670, 2007.

. Progress and recent trends in biodiesel fuels. Energy Conversion and Management, v. 50, p. 14-34, 2009.

Green energy and technology: biorefineries. London: Springer, 2010.

ENERGY INFORMATION ADMINISTRATION EIA. International Energy Statistics. Disponível em: <http://www.eia.gov/cfapps/ipdbproject/IEDIndex3. $\mathrm{cfm}$ ?tid $=90 \&$ pid $=44 \&$ aid $=8>$. Acesso em: 22 abr. $2015 \mathrm{a}$.

EUROBSERV'ER. Biofuels Barometer. Europa: EurObserv'ER, 2010.

Biofuels Barometer. Europa: EurObserv'ER, 2014.

EUROPEAN BIODIESEL BOARD - EBB. Statistics. Disponível em: <http://www.ebb-eu.org/>. Acesso em: 30 nov. 2015.

EUROPEAN COMMISSION. Diretiva 2009/28/EC do Parlamento Europeu e do Conselho, de 23 de abril de 2009. Jornal Oficial da União Europeia, Bruxelas, 5 jun. 2009a.

. Diretiva 2009/30/EC do Parlamento Europeu e do Conselho, de 23 de abril de 2009. Jornal Oficial da União Europeia, Bruxelas, 5 jun. 2009b.
FARINA, E. M. M. Q., AZEVEDO, P. F. e SAES, M. S. M. Competitividade: mercado, estado e organizações. São Paulo: Singular, 1997.

FONG, D. Y. T., HO, S. Y. e LAM, T. H. Evaluation of internal reliability in the presence of inconsistent responses. Health and Quality of Life Outcomes, v. 8, n. 27, p. 1-10, 2010.

GIAMPIETRI, E. et al. Comparing Italian and Brazilian consumers' attitudes towards Short Food Supply Chains. Rivista di Economia Agraria, v. 1, n. 1 (Supplemento), p. 246-254, 2016

GREIF, A. e LAITIN, D. D. A theory of endogenous institutional change. American Political Science Review, v. 98, n. 4, p. 633-652, nov. 2004.

GUIMARÃES, L. G. A. et al. Viabilidade da produção de oleaginosas para a cadeia produtiva do biodiesel pela agricultura familiar. In: CONGRESSO BRASILEIRO DE CUSTOS, 16, 2009, Fortaleza, Anais... Fortaleza, 03 a 05 de novembro de 2009. p. 1-16.

GUIMARÃES JR, F. R. F. et al. Análise de preferência declarada para estudar a utilidade da produção de oleaginosas. Produção, v. 23, n. 4, p. 846-857, out./dez. 2013.

HAIR JR, J. F. et al. Multivariate data analysis. 7. ed. New Jersey: Prentice Hall-Pearson, 2009.

HAYEK, F. A. V. The use of knowledge in society. American Economic Review, v. XXXV, n. 4, p. 519-530, set. 1945.

HOF, M. Questionnaire evaluation with factor analysis and Cronbach's alpha. 2012. Disponível em: <http://www. let.rug.nl/nerbonne/teach/rema-stats-meth-seminar/ student-papers/MHof-QuestionnaireEvaluation-2012Cronbach-FactAnalysis.pdf>. Acesso em: 15 mar. 2017.

IMASATO, T. Estratégia, legitimidade e biocombustíveis: uma perspectiva geopolítica. 2010. 214 f. Tese (Doutorado em Administração) - Escola Brasileira de Administração Pública e de Empresas da Fundação Getúlio Vargas, Rio de Janeiro, 2010.

KAISER, H. F. An index of factorial simplicity. Psychometrika, v. 39, n. 1, mar. 1974.

KHALIL, C. N. As tecnologias de produção de biodiesel. In: FERREIRA, J. R. e CRISTO, C. M. P. N. O futuro da indústria: biodiesel. Brasília: MDIC, 2006, p. 83-90.

KRAUSE, L. C. Desenvolvimento do processo de produção de biodiesel de origem animal. 2008. 147 f. Tese (Doutorado em Química) - Instituto de Química da Universidade Federal do Rio Grande do Sul, Porto Alegre, 2008.

LAPASSADE, G. Grupos, organizações e instituições. Rio de Janeiro: Francisco Alves, 1985. 
McCORMICK, K. e KÅBERGER, T. Exploring a pioneering bioenergy system: the case of Enköping in Sweden. Journal of Clear Production, n. 13, p. 1003-1014, 2005.

MINGOTI, S. A. Análise de dados através de métodos de estatística multivariada: uma abordagem aplicada. Belo Horizonte: UFMG, 2005.

NORTH, D. C. Transaction costs, institutions, and economic performance. San Francisco/California: International Center for Economic Growth, 1992.

Understanding the process of economic change. Princeton: Princeton University Press, 2005.

OKADA, S. I. Análise dos pontos críticos de sucesso na cadeia produtiva do biodiesel no Centro-Oeste brasileiro: um subsídio à gestão estratégica. 2008. 153 f. Dissertação (Mestrado em Agronegócio) - Universidade Federal de Goiás, Goiânia, 2008.

OLIVEIRA, S. V. Os custos de transação da cadeia produtiva do biodiesel à base de soja no Rio Grande do Sul: impactos sobre a gestão das cadeias de suprimentos das usinas instaladas. 2010. 156 f. Dissertação (Mestrado em Extensão Rural) - Universidade Federal de Santa Maria, Santa Maria, 2010.

OLIVÉRIO, J. L. O panorama brasileiro de biodiesel na visão da indústria de equipamentos. In: FERREIRA, J. R. e CRISTO, C. M. P. N. O futuro da indústria: biodiesel. Brasília: MDIC, 2006, p. 105-126.

OCDE. Patents and innovation: trends and policy challenges. Paris: OCDE, 2004.

PEDROTI, P. M. Os desafios do desenvolvimento e da inclusão social: o caso do arranjo político-institucional do Programa Nacional de Produção de Uso do Biodiesel. Texto para Discussão n. 1858. Rio de Janeiro, IPEA, ago. 2013.

PRADO, J. N. e VIEIRA, W. C. Leilões de biodiesel conduzidos pela ANP. Nexus Econômicos, v. IV, n. 6, p. 67-88, jun. 2010.

PRATES, C. P. T., PIEROBON, E. C. e COSTA, R. C. da. Formação do mercado de biodiesel no Brasil. BNDES Setorial, Rio de Janeiro, n. 25, p. 39-64, mar. 2007.

QUINTELlA, C. M. et al. Cadeia do biodiesel da bancada à indústria: uma visão geral com prospecção de tarefas e oportunidades para P\&D\&I. Química Nova, v. 32, n. 3, p. 793-808, 2009.

RICO, J. A. P. Biocombustíveis, alimentos e petróleo: uma análise retrospectiva da experiência brasileira. 2013. 189 f. Tese (Doutorado em Energia) - Escola Politécnica / Faculdade de Economia e Administração / Instituto de Energia e Ambiente / Instituto de Física da Universidade de São Paulo, São Paulo, 2013.
ROCHA JR, W. F. Análise do agronegócio da erva-mate com o enfoque da nova economia institucional e o uso da matriz estrutural prospectiva. 2001. $133 \mathrm{f}$. Tese (Doutorado em Engenharia de Produção) - Universidade Federal de Santa Catarina, Florianópolis, 2001.

ROSILLO-CALLE, F, PELKMANS, L. e WALTER, A. A global overview of vegetable oils, with reference to biodiesel. A Report for the IEA Bioenergy Task 40. IEA Bioenergy, 2009.

SANTOS, S. F., BORSCHIVER, S. e SOUZA, V. Fatores determinantes para a sustentabilidade da cadeia produtiva do biodiesel no Brasil. In: CONGRESSO LATINO-IBEROAMERICANA DE GESTÃO DE TECNOLOGIA, 15., 2013, Porto. Anais... Porto, 2013. p. 3695-3720.

SUNGATE. Global biodiesel consumption in 2016. Disponível em: <http://www.sungate-analytics.com/ blog/2015/11/24/global-biodiesel-consumption > . Acesso em: 18 set 2015.

UBRABIO - UNIÃO BRASILEIRA DO BIODIESEL E BIOQUEROSENE. O combustível da sustentabilidade. Biodiesel em foco, Brasília, ano VI, n. 6, 2015.

UNITED STATES DEPARTMENT OF AGRICULTURE - USDA. EU Biofuels Annual Report 2014. GAIN Report Number NL4025, July 2014.

WEISSENBURGER-MOSER, L. et al. A principal factor analysis to characterize agricultural exposures among Nebraska veterans. Journal of Exposure Science and Environmental Epidemiology, n. 27, p. 214-220, 2017.

WILLIAMSON, O. The economic institutions of capitalism: firms, markets, relational contracting. Nova York: Free Press, 1985.

. The new institutions economics: taking stocks, looking ahead. Journal of Economic Literature, v. XXXVIII, p. 595-613, set. 2000.

ZEZZA, A. Bioenergie: quali opportunità per l'agricoltura italiana. Napoli: Edizione Scientifiche Italiane, 2008. (Collana: Studi \& Ricerche INEA).

ZYLBERSZTAJN, D. Estruturas de governança $e$ coordenação do agribusiness: uma aplicação da Nova Economia das Instituições. 1995. 241 f. Tese (Livre Docência) - Departamento de Administração da Faculdade de Economia, Administração e Contabilidade da Universidade de São Paulo, São Paulo, 1995.

Conceitos gerais, evolução e apresentação do sistema agroindustrial. In: ZYLBERSZTAJN, D.; NEVES, M. F. (Orgs.). Economia e gestão dos negócios agroalimentares. São Paulo: Pioneira, 2000. 